\title{
Is there Still a Place for Perfusion SPECT in the Diagnosis of Dementia?
}

\author{
Klaus P. Ebmeier* \\ Department of Psychiatry, University of Oxford, Warneford Hospital, Oxford, UK
}

\begin{abstract}
Although research interest within functional imaging has moved towards applications of MRI, such as BOLD and perfusion imaging, there is a wealth of clinical experience in emission tomographic imaging techniques that make the use of these modalities relevant for the decades to come. This review touches upon the technical and practical issues that distinguish SPECT from PET, describes perfusion and metabolic changes observed in the dementias, compares the clinical utility of the two techniques, and reports data on clinical sensitivity and specificity, as well as diagnostic head-to head comparisons in dementia, and specifically Alzheimer's disease. While few centres have a genuine choice between PET and SPECT, either appears to be good enough to help with the differential diagnosis of dementia in difficult cases.
\end{abstract}

Keywords: Single photon emission tomography, positron emission tomography, dementia, Alzheimer's disease, mild cognitive impairment, diagnosis.

\section{INTRODUCTION}

Radionuclide-based imaging, such as single photon emission computed tomography (SPECT) and positron emission tomography (PET), have been available for the diagnosis of dementia since the second half of the last century, but their impact on daily diagnostic practice has been limited. Opinions differ about the relative advantages of PET and SPECT in the diagnosis of the dementias [1-4]. Of the industrialised countries, particularly Europe and Japan still use SPECT frequently for diagnostic purposes in dementia [5], in general the US literature tends to ignore clinical SPECT and expects FDG-PET to be available.

\section{Intrinsic Limitations of SPECT}

In contrast to PET where the physics of positron annihilation provide directional information that helps with the three-dimensional reconstruction of the activity map, in SPECT collimators are used in order to focus the signal onto the detector(s). In contrast to PET where the physics of positron annihilation provide directional information that helps with the three-dimensional reconstruction of the activity map, in SPECT collimators are used in order to focus the signal onto the detector(s). This directional filtering only allows for a small proportion of emitted photons to be detected, which limits the sensitivity of SPECT, in addition scattered photons are excluded with energy filters. In contrast to quantitative attenuation modelling with transmission scans in PET, attenuation is often ignored in SPECT or resolved making the assumption of homogenous attenuation in the head. SPECT gamma emitters with half-lives of 6-12 hours are employed, so that the tracers can be generated commercially some distance from the scanner. The long half-life of the radioactive label makes only a limited numbers of exposures possible. The gamma emitting nuclei ( ${ }^{123}$ Iodine and ${ }^{99 \mathrm{~m}}$ Technetium)

*Address correspondence to this author at the Department of Psychiatry, University of Oxford, Warneford Hospital, Oxford OX3 7JX, UK; Tel/Fax: (44)1865-226469; E-mail: klaus.ebmeier@psych.ox.ac.uk are large and tend to change the pharmacology of the tracer after substitution (Table 1). This requires a repetition of the pharmacological development work necessary to describe binding characteristics, and may explain the limited number of SPECT-ligands commercially available.

Table 1. Some Common Perfusion Tracers for SPECT

\begin{tabular}{|c|c|}
\hline \multicolumn{1}{c}{ Tracer } & Isotope-Mode \\
\hline Hexamethylpropyleneamine oxime (HMPAO) & ${ }^{99 \mathrm{~m}}$ Tc- SPECT \\
\hline N-isopropyl-p-iodoamphetamine (IMP) & ${ }^{123}$ I-SPECT \\
\hline Ethylene cysteinate dimer (ECD) & ${ }^{99 \mathrm{~m}}$ Tc-SPECT \\
\hline
\end{tabular}

\section{Image Analysis Methods}

Images are usually analysed qualitatively using visual inspection, or quantitatively with a variety of semiautomated methods [6]. Qualitative visual assessment of PET scans can be reliable (intra-observer $\kappa=0.56$; interobserver $\kappa=0.51$ ) [7], as can be SPECT $[8,9]$, particularly if well defined classification criteria are used $[10,11]$.

Typically for research purposes, but occasionally also in a clinical context, regions of interest (ROIs) are superimposed over the brain activity map, often following the underlying structural anatomy. Mean uptake values are averaged within these regions and compared within or between subjects [12]. Quantitative methods, such as the automated multi-ROI programme 3DSRT $[13,14]$, statistical parametric mapping [15-17], discriminant function analysis [18-20], three-dimensional stereotactic surface projection [21] and neural network analysis [22-26] have been added to the research tools available in PET and SPECT. Adding structural information from MRI or CT improves clinical and research interpretations of functional scans [19, 27-30]. Fig. (1) shows an example of visual and quantitative analysis of SPECT and how this can be helpful in an unusual case. 
(a)

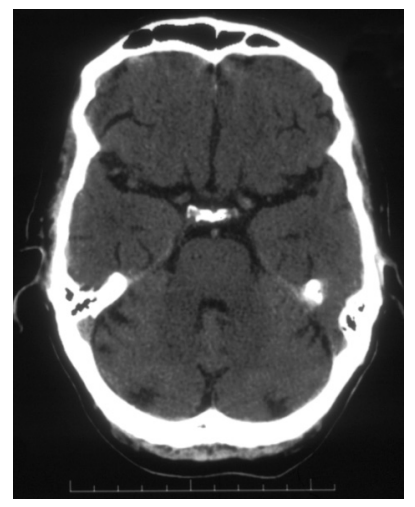

(b)

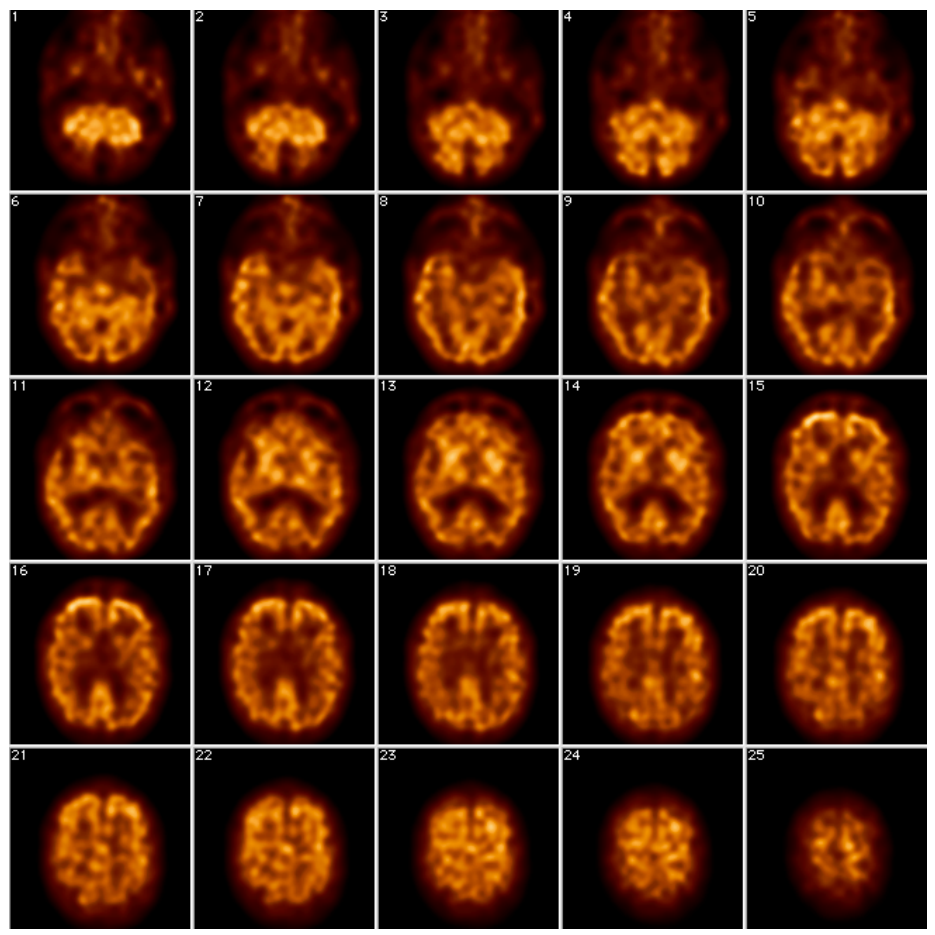

(c)

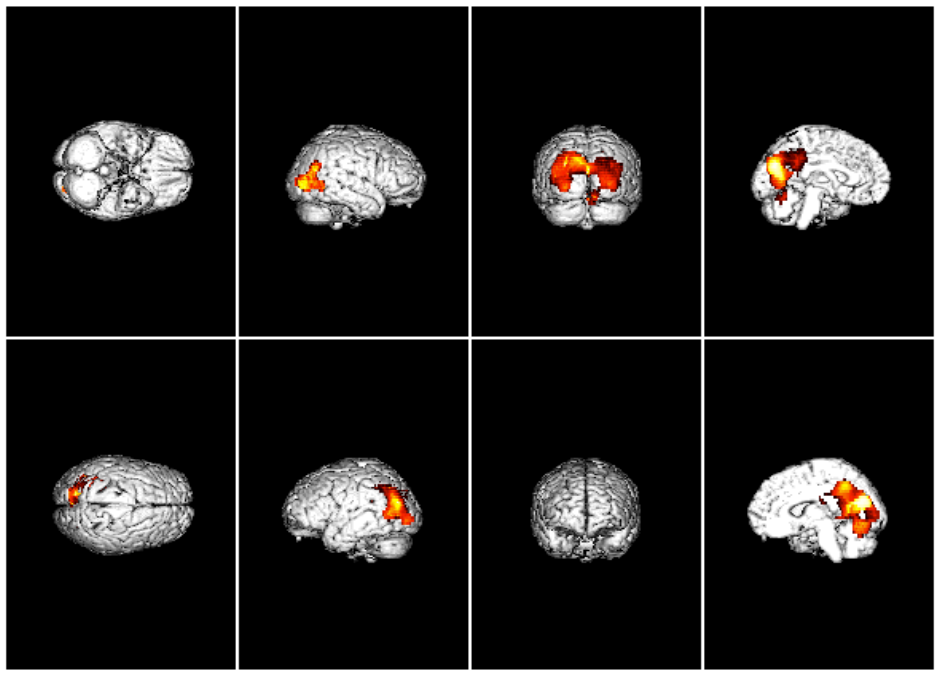

Fig. (1). A 81 year-old man with a clinical diagnosis of 'frontal lobe dysfunction' showing no evidence of significant atrophy on brain Computed Tomography (a) but evidence of Alzheimer-type neurodegenerative pattern on both visual (b) and voxel-based quantitative (c) analysis. 


\section{The Practical Scope of Clinical PET and SPECT in Dementia}

Before discussing the clinical use of perfusion and metabolic imaging in dementia, it will help to reflect on the possible roles such imaging can play, in order to identify the kind of evidence necessary to support its use. Aspects of the use of imaging include stage of the disease, differential diagnosis, the need to predict prognosis and treatment response, and clinical setting, i.e. usual grounds for referral, such as the presence of symptoms, signs, screening, or treatment resistance. An important factor is the availability and efficacy of alternative diagnostic methods, as well as the nature of conditions that affect patients alternatively to, or concurrently with, Alzheimer's disease (AD), as well confounders, such as age. On theoretical grounds very early diagnosis may be the ideal, as potential treatments may be most effective when brain damage is minimal. However, for economical and practical reasons patients are very unlikely to be screened using imaging methods. Detection before the appearance of symptoms is, therefore, unlikely. 'Dementia' is a clinical diagnosis and crucially depends on impairments of activities of daily living [31]. As it is the gold standard in vivo, it is more sensitive than, for example, a typical screening scale, such as the mini mental state examination (MMSE [32]). Clinical judgement makes it possible to diagnose early dementia in people of varying backgrounds, ranging from a university professor with a MMSE score of 29 out of 30 to a person with Down's syndrome whose MMSE score has always been in the "dementia range". It also allows for the exclusion of conditions, such as depression, that may present with both memory impairment and reduced activities of daily living scores. The myth of psychiatrists' inability to differentiate depression from dementia in old age is mainly propagated for the benefit of research funding agencies. Most imaging will therefore take place after a clinical diagnosis of dementia or at least mild cognitive impairment (MCI) has been made.

\section{Patterns of Perfusion-SPECT Abnormalities in the Dementias}

The above implies that the purpose of imaging will be mainly the differential diagnosis of the causes of dementia [33]. From this point of view, a specific imaging modality that has some affinity with the causal mechanism of the dementia in question will be the ideal approach. Examples for this are imaging of the dopamine transporter in dementia of the Lewy body type [34] or amyloid imaging in AD [35]. While this strategy seems to bear fruit for the dopamine transporter tracer, Alzheimer's plaques are found in a substantial part of the brains of non-demented older people [36], so that some non-demented people have positive amyloid scans. Functional imaging, in particular with tracers that mirror brain perfusion or glucose uptake, will reflect brain function (at rest) and to some extent anatomical changes, such as atrophy, although the resolution of these imaging modalities tend to be lower than that of structural scans. Images will therefore in general rather reflect the pattern of impairment than be directly associated with diagnosis. Moreover, Alzheimer's and vascular dementia can occur together so that mixed imaging patterns are likely to be found in a significant proportion of patients. The natural history of symptoms in $\mathrm{AD}$ varies in terms of symptoms and clinical signs, so that a variable pattern of brain changes may be expected. At an advanced stage, most dementias tend to involve large portions of association cortex, so spatial patterns of reduced perfusion or metabolism that help differential diagnosis may disappear.

$\mathrm{AD}$ initially presents with posterior cingulate [37, 38] or medial temporal [39-42] reductions in brain activity, followed by bilateral posterior temporo-parietal reductions [10, 20, 4347]. Patients with mild cognitive impairment and temporoparietal association area, posterior cingulate, or hippocampal reductions in blood flow or glucose metabolism are more likely to go into progressive cognitive decline [48]. Later, prefrontal activity reductions appear. Herholz and colleagues have suggested computing a ratio of association cortex to primary sensory-motor cortex activity as a diagnostic index for AD [49]. Patients, who initially present with functional impairment and reduced activity of anterior parts of the brain, have a variety of underlying pathologies, ranging from Pick's to tauopathies, to ubiquitin, and microvacuolar type histology [50]. In vascular dementia patchy lesions of brain perfusion are often asymmetrical in distribution, or localised in "watershed" regions of the brain. Patients with Lewy-body dementia show little difference in perfusion patterns from $\mathrm{AD}$, although occipitotemporal changes have been described [51, 52].

\section{Sensitivity and Specificity}

In order to estimate the sensitivity and specificity of an imaging method, a "gold standard" has to be available that provides, so to say, the denominators of the formula. While dementia is a clinical diagnosis, the differential diagnosis is even more dependent on 'soft' items of information. Formal diagnostic criteria exist, such as the NINCDS-ADRDA criteria for $\mathrm{AD}$ [53], the NINDS-AIREN criteria for vascular dementia [54], and revised criteria for dementia with Lewy bodies [55]. Interestingly, such criteria are usually not very sensitive, but show high specificity compared with post mortem criteria. Should functional imaging then be designed to reflect the distribution and severity of brain cell loss, or patients' functional impairment, their symptoms and signs? By the time the brain histology is known, a number of confounding factors will have intervened: additional illness and treatment, and selection bias with low uptake of post mortem examinations. For this reason, the significance of abnormalities in MCI, usually defined as subjective and objective cognitive impairment without functional impairment, are difficult to assess: unless brains come to pathological examination shortly after the scan, intervening illness is likely to blur the picture. At best, patterns of hypoperfusion in MCI patients that are typical of AD will predict later conversion to dementia [56-59]. Of greatest interest is, of course, whether imaging can inform treatment decisions. Without any specific effective treatments, "predictive validity" means follow-up within 2-3 years to confirm clinical diagnosis, and that (hopefully) imaging results at baseline predict clinical outcome. Using data pooled from 27 studies, we found that SPECT successfully discriminated between healthy elderly controls and $\mathrm{AD}$ with a pooled sensitivity of $77 \%$ against a pooled specificity of $89 \%$ [60]. Used in addition to structural imaging, functional imaging appears to increase diagnostic sensitivity in $\mathrm{AD}$, with blood flow and metabolism first affected in posterior cingulate gyrus and precuneus, then advancing to medial temporal structures and parieto-temporal association cortex [61]. Entorhinal cortex and hippocampal metabolic 
reductions have been used to discriminate cognitively normal volunteers from subjects with mild cognitive impairment with a diagnostic accuracy of $81 \%$, and from AD using the temporal neocortex with a diagnostic accuracy of $100 \%$ [62]. Similarly, the ratio of deoxyglucose uptake in association cortex over primary sensory-motor cortex of patients with mild cognitive deficits predicted progression to AD [49]. As AD advances, bilateral parieto-temporal perfusion deficits become more frequent and severe [63] with a reported odds ratio (OR) of 5.2 (95\% CI 1.1-24.4) for moderate AD (MMSE:10-17) and an OR of $17.0(95 \%$ CI 3.1-94.2) for severe AD (MMSE<10).

\section{Pathological Confirmation of Scan Diagnosis}

Increasingly, patient cohorts are followed up till postmortem. The advantages and disadvantages of pathological diagnosis as a "gold standard" have been discussed above. While diagnostic verification by 3 year clinical follow-up suggested that regional brain metabolism was a sensitive indicator of $\mathrm{AD}$ [64], pathological verification in the same study confirmed a sensitivity of $94 \%$ (91 out of 97 subjects) and a specificity of $73 \%$ (30 out of 41 subjects) compared with other patients presenting with dementia. Overall diagnostic accuracy of 55 patients who presented with questionable or mild dementia was $89 \%$ [64]. In a diagnostically challenging group of patients, sensitivity and specificity of PET compared with a histological diagnosis of AD were $93 \%$ and $63 \%$, respectively; sensitivity and specificity of the clinical diagnosis of probable $\mathrm{AD}$ versus histology were $63 \%$ and $100 \%$, respectively, so that the overall diagnostic accuracy of PET at $82 \%$ was better than clinical diagnosis at 73\% [45]. Two comparable SPECT studies with pathological verification of $\mathrm{AD}$ reported sensitivities of $86 \%$ and $63 \%$ against specificities of $73 \%$ and $93 \%$, respectively $[65,66]$.

\section{Follow-Up Studies}

Longitudinal functional imaging studies suggest that patients with more severe temporo-parietal perfusion or metabolic deficits show a more rapid cognitive and general decline over time $[67,68]$. Patients with MCI, who initially show regional cerebral blood flow ( $\mathrm{rCBF}$ ) decreases in the posterior cingulate, parietal and precuneus regions, subsequently show additional abnormalities in the hippocampus and parahippocampus when a clinical diagnosis of AD can be made [37, 69]. Specific neuropsychological abnormalities that occur during the natural history of single AD patients, can be predicted by early metabolic asymmetries in their association cortices [70]. This hints at compensatory mechanisms in the brain that allow normal psychological function, when abnormalities can already be discovered in strategic brain regions [71]. Such compensatory plasticity may be responsible for the observation that pre-morbid IQ and word reading ability are inversely correlated with metabolism in AD [72]. Longitudinal studies during treatment are of course of particular interest, but are in their infancy, mainly due to the state of development of treatments in $\mathrm{AD}$ [43].

\section{Guidelines and Consensus Statements}

Parieto-temporal deficits in PET/SPECT of AD and widespread irregular lesions in vascular dementia have been generally acknowledged [73], but guidelines do not recommend the routine clinical use of SPECT [74, 75]. Similarly, there is little evidence to support a role for PET in the clinical evaluation of patients with suspected or established dementia [76]. The American College of Radiology recommends functional imaging for cases that are difficult to diagnose [77]. More recent consensus statements concur that imaging techniques have an important role to play in the diagnosis and assessment of dementia and specifically AD [78-82]. In the UK, both English and Scottish guidelines recommend imaging, in particular SPECT, for the differential diagnosis of difficult cases $[83,84]$.

\section{SPECT vs PET}

Whole brain correlations of abnormal tracer uptake between PET and SPECT in the same subjects were relatively modest $(\mathrm{r}=0.43)$, with higher correlations in the temporo-parietal and posterior cingulate association cortices [4]. In the same study, PET with statistical parametric mapping (SPM) discriminated better between healthy volunteers and patients with $\mathrm{AD}$ than SPECT. Using temporo-parietal reductions as a diagnostic criterion, Messa and colleagues compared PET and SPECT in participants with probable $\mathrm{AD}$ and normal controls, and determined a sensitivity of $100 \%$ for PET and $90 \%$ for SPECT [85]. Ishii and colleagues compared F-18-FDG-PET with IMPSPECT in patients with DLB; reductions of tracer uptake were found in posterior parietal and to a lesser extent in occipital cortex, with PET appearing to be more sensitive to abnormalities [86]. Clinical utility in predicting outcome appears greater for FDG-PET than for SPECT [87, 88], although opinions about their respective merits differ [1-3].

\section{CONCLUSON}

The choice between PET and SPECT then appears to be marginal but clearly in favour of PET. In real life, few clinicians will have the choice between the two, so that the decision will be more between functional scan and no functional scan. From the above data it seems that SPECT is a creditable alternative to ${ }^{18}$ FDG-PET. While perfusion MRI is being used in research to good effect, its clinical availability as an alternative imaging modality will require more time to be established in most places [89].

\section{ACKNOWLEDGEMENT}

I was funded for this work by the Gordon Edward Small's Charitable Trust (Scottish Charity Register Number: SC008962)

\section{REFERENCES}

[1] Pupi A, Nobili FM. PET is better than perfusion SPECT for early diagnosis of Alzheimer's disease -- against. Eur J Nucl Med Mol Imaging 2005; 32: 1466-72.

[2] Nihashi T, Yatsuya H, Hayasaka K, et al. Direct comparison study between FDG-PET and IMP-SPECT for diagnosing Alzheimer's disease using 3D-SSP analysis in the same patients. Radiol Med 2007; 25: 255-62.

[3] Yuan Y, Gu ZX, Wei WS. Fluorodeoxyglucose-positron-emission tomography, single-photon emission tomography, and structural MR imaging for prediction of rapid conversion to Alzheimer disease in patients with mild cognitive impairment: a meta-analysis. Am J Psychol 2009; 30: 404-10.

[4] Herholz K, Schopphoff H, Schmidt M, et al. Direct comparison of spatially normalized PET and SPECT scans in Alzheimer's disease. J Nucl Med 2002; 43: 21-6.

[5] Ebmeier KP. SPECT in Dementia. Ebert D, Ebmeier KP, Kaschka WP Gattaz WF, Eds. Basel: Karger Verlag 2003.

[6] Matsuda H. Role of neuroimaging in Alzheimer's disease, with emphasis on brain perfusion SPECT. J Nucl Med 2007; 48: 1289-300. 
[7] Hoffman JM, Hanson MW, Welsh KA, et al. Interpretation variability of (18)FDG-positron emission tomography studies in dementia. Invest Radiol 1996; 31: 316-22.

[8] Hellman RS, Tikofsky RS, Van H, Coade G, Carretta R, Hoffmann RG. A multi-institutional study of interobserver agreement in the evaluation of dementia with $\mathrm{rCBF} / \mathrm{SPET}$ technetium-99m exametazime (HMPAO). Eur J Nucl Med 1994; 21: 306-13.

[9] Pasquier F, Lavenu I, Lebert F, Jacob B, Steinling M, Petit H. The use of SPECT in a multidisciplinary memory clinic. Dement Geriatr Cogn Dis 1997; 8: 85-91.

[10] Holman BL, Johnson KA, Gerada B, Carvalho PA, Satlin A. The scintigraphic appearance of Alzheimers-disease - a prospective-study using technetium-99m-HMPAO SPECT. J Nucl Med 1992; 33: 181-5.

[11] Sloan EP, Fenton GW, Kennedy NS, MacLennan JM. Electroencephalography and single photon emission computed tomography in dementia: a comparative study. Psychol Med 1995; 25: 631-8.

[12] Defevre LJ, Leduc V, Duhamel A, et al. Technetium HMPAO SPECT study in dementia with Lewy bodies, Alzheimer's disease and idiopathic Parkinson's disease. J Nucl Med 1999; 40: 956-62.

[13] Kobayashi S, Tateno M, Utsumi K, et al. Quantitative analysis of brain perfusion SPECT in Alzheimer's disease using a fully automated regional cerebral blood flow quantification software, 3DSRT. J Neurol Sci 2008; 264: 27-33.

[14] Tateno M, Utsumi K, Kobayashi S, et al. Usefulness of a blood flow analyzing program 3DSRT to detect occipital hypoperfusion in dementia with Lewy bodies. Prog Neuropsychopharmacol Biol Psychiatry 2008; 32: 1206-9.

[15] Friston KJ, Holmes AP, Worsley KJ, Poline J-P, Frith CD, Frackowiak RSJ. Statistical parametric maps in functional imaging: a general linear approach. Hum Brain Map 1995; 2: 189-210.

[16] Soonawala D, Amin T, Ebmeier KP, et al. Statistical parametric mapping of 99mTc-HMPAO-SPECT images for the diagnosis of Alzheimer's disease: normalizing to cerebellar tracer uptake. Neuroimage 2002; 17: 1193-202.

[17] Bagnasco S, Beltrame F, Canesi B, et al. Early diagnosis of Alzheimer's disease using a grid implementation of statistical parametric mapping analysis. Stud Health Technol Inform 2006; 120: 69-81.

[18] Mahony D, Coffey J, Murphy J, et al. The discriminant value of semiquantitative SPECT data in mild Alzheimer's disease. J Nucl Med 1994; 35: 1450-5.

[19] O'Brien JT, Ames D, Desmond P, et al. Combined magnetic resonance imaging and single-photon emission tomography scanning in the discrimination of Alzheimer's disease from age-matched controls. Int Psychogeriatr 2001; 13: 149-61.

[20] Volkow ND, Zhu W, Felder CA, et al. Changes in brain functional homogeneity in subjects with Alzheimer's disease. Psychol Res Neuroimaging 2002; 114: 39-50.

[21] Burdette JH, Minoshima S, Vander Borght T, Tran DD, Kuhl DE. Alzheimer disease: improved visual interpretation of PET images by using three-dimensional stereotaxic surface projections. Radiology 1996; 198: 837-43.

[22] Chan KH, Johnson KA, Becker JA, et al. A neural network classifier for cerebral perfusion imaging. J Nucl Med 1994; 35: 771-4.

[23] Dawson MR, Dobbs A, Hooper HR, McEwan AJ, Triscott J, Cooney J. Artificial neural networks that use single-photon emission tomography to identify patients with probable Alzheimer's disease. Eur J Nucl Med 1994; 21: 1303-11.

[24] deFigueiredo RJ, Shankle WR, Maccato A, et al. Neural-network-based classification of cognitively normal, demented, Alzheimer disease and vascular dementia from single photon emission with computed tomography image data from brain. Proc Natl Acad Sci USA 1995; 92 : 5530-4.

[25] Kippenhan JS, Barker WW, Nagel J, Grady C, Duara R. Neuralnetwork classification of normal and Alzheimer's disease subjects using high-resolution and low-resolution PET cameras. J Nucl Med 1994; 35: 7-15.

[26] Page MP, Howard RJ, O`Brien JT, Buxton T, Pickering AD. Use of neural networks in brain SPECT to diagnose Alzheimer's disease. $\mathrm{J}$ Nucl Med 1996; 37: 195-200.

[27] Callen DJA, Black SE, Caldwell CB. Limbic system perfusion in Alzheimer's disease measured by MRI- coregistered HMPAO SPET. Eur J Nucl Med Mol Imaging 2002; 29: 899-906.

[28] Mattman A, Feldman H, Forster B, et al. Regional HmPAO SPECT and CT measurements in the diagnosis of Alzheimer's disease. Can J Neurol Sci 1997; 24: 22-8.
[29] Scheltens P, Launer LJ, Barkhof F, Weinstein HC, Jonker C. The diagnostic value of magnetic resonance imaging and technetium $99 \mathrm{~m}$ HMPAO single-photon-emission computed tomography for the diagnosis of Alzheimer disease in a community-dwelling elderly population. Alzheimer Dis Assoc Disord 1997; 11: 63-70.

[30] Varma AR, Adams W, Lloyd JJ, et al. Diagnostic patterns of regional atrophy on MRI and regional cerebral blood flow change on SPECT in young onset patients with Alzheimer's disease, frontotemporal dementia and vascular dementia. Acta Neurol Scand 2002; 105: 261-9.

[31] American Psychiatric Association. Diagnostic and Statistical Manual of Mental Disorders, $4^{\text {th }}$ ed. Washington, DC: Am Psychiatric Assoc 1994.

[32] Folstein MF, Folstein SE, McHugh PR. "Mini-mental state". A practical method for grading the cognitive state of patients for the clinician. $\mathrm{J}$ Psychiatr Res 1975; 12: 189-98.

[33] Dougall NJ, Bruggink S, Ebmeier KP. Systematic review of the diagnostic accuracy of 99mTc-HMPAO-SPECT in dementia. Am J Geriatr Psychiatry 2004; 12: 554-70.

[34] O'Brien JT, McKeith IG, Walker Z, et al. Diagnostic accuracy of 123IFP-CIT SPECT in possible dementia with Lewy bodies. Br J Psychiatry 2009; 194: 34-9.

[35] Ikonomovic MD, Klunk WE, Abrahamson EE, et al. Post-mortem correlates of in vivo PiB-PET amyloid imaging in a typical case of Alzheimer's disease. Brain 2008; 131: 1630-45.

[36] Ince PG. Pathological correlates of late-onset dementia in a multicentre, community-based population in England and Wales: neuropathology group of the medical research council cognitive function and ageing study (MRC CFAS)1. Lancet 2001; 357: 169-75.

[37] Minoshima S, Giordani B, Berent S, Frey KA, Foster NL, Kuhl DE. Metabolic reduction in the posterior cingulate cortex in very early Alzheimer's disease. Ann Neurol 1997; 42: 85-94.

[38] Rossor MN, Kennedy AM, Frackowiak RSJ. Clinical and neuroimaging features of familial Alzheimer's disease. Neurobiol Alzheimers Dis 1996; 777: 49-56.

[39] Elgh E, Sundstrom T, Nasman B, Ahlstrom R, Nyberg L. Memory functions and rCBF (99m)Tc-HMPAO SPET: developing diagnostics in Alzheimer's disease. Eur J Nucl Med Mol Imaging 2002; 29: 1140-8.

[40] Ishii K, Sakamoto S, Sasaki M, et al. Cerebral glucose metabolism in patients with frontotemporal dementia. J Nucl Med 1998; 39: 1875-8.

[41] Lee YC, Liu RS, Liao YC, et al. Statistical Parametric Mapping of Brain SPECT Perfusion Abnormalities in Patients with Alzheimer's Disease. Eur Neurol 2003; 49: 142-5.

[42] Villa G, Cappa A, Tavolozza M, et al. Neuropsychological tests and [99mTc]-HM PAO SPECT in the diagnosis of Alzheimer's dementia. J Neurol 1995; 242: 359-66.

[43] Alexander GE, Chen K, Pietrini P, Rapoport SI, Reiman EM. Longitudinal PET evaluation of cerebral metabolic decline in dementia: a potential outcome measure in Alzheimer's disease treatment studies. Am J Psychol 2002; 159: 738-45.

[44] Herholz K, Salmon E, Perani D, et al. Discrimination between Alzheimer dementia and controls by automated analysis of multicenter FDG PET. Neuroimage 2002; 17: 302-16.

[45] Hoffman JM, Welsh-Bohmer KA, Hanson M, et al. FDG PET imaging in patients with pathologically verified dementia. J Nucl Med 2000; 41: 1920-8.

[46] Okamura N, Arai H, Higuchi M, et al. [18F]FDG-PET study in dementia with Lewy bodies and Alzheimer's disease. Prog Neuropsychopharmacol Biol Psychol 2001; 25: 447-56.

[47] Masterman DL, Mendez MF, Fairbanks LA, Cummings JL. Sensitivity, specificity, and positive predictive value of technetium 99-HMPAO SPECT in discriminating Alzheimer's disease from other dementias. J Geriatr Psychol Neurol 1997; 10: 15-21.

[48] Wolf H, Jelic V, Gertz HJ, Nordberg A, Julin P, Wahlund LO. A critical discussion of the role of neuroimaging in mild cognitive impairment. Acta Neurol Scand 2003; 179 (Suppl): 52-76.

[49] Herholz K, Nordberg A, Salmon E, et al. Impairment of neocortical metabolism predicts progression in Alzheimer's disease. Dement Geriatr Cogn Dis 1999; 10: 494-504.

[50] Mann DMA. The genetics and molecular pathology of frontotemporal lobar degeneration. In: Burns A, O'Brien J, Ames D, Eds. Dementia. $3^{\text {rd }}$ ed. London: Hodder-Arnold 2005; pp. 689-701.

[51] Ishii K, Yamaji S, Kitagaki H, Imamura T, Hirono N, Mori E. Regional cerebral blood flow difference between dementia with Lewy bodies and AD. Neurology 1999; 53: 413-6.

[52] Minoshima S, Foster NL, Sima AAF, Frey KA, Albin RL, Kuhl DE. Alzheimer's disease versus dementia with Lewy bodies: Cerebral 
metabolic distinction with autopsy confirmation. Ann Neurol 2001; 50: 358-65.

[53] McKhann G, Drachman D, Folstein M, Katzman R, Price D, Stadlan EM. Clinical diagnosis of Alzheimer's disease: report of the NINCDSADRDA Work Group under the auspices of Department of Health and Human Services Task Force on Alzheimer's Disease. Neurology 1984; 34: 939-44.

[54] Erkinjuntti T. Clinical criteria for vascular dementia: the NINDSAIREN criteria. Dementia 1994; 5: 189-92.

[55] McKeith IG. Consensus guidelines for the clinical and pathologic diagnosis of dementia with Lewy bodies (DLB): report of the Consortium on DLB International Workshop. J Alzheimers Dis 2006; 9: 417-23.

[56] Borroni B, Anchisi D, Paghera B, et al. Combined 99mTc-ECD SPECT and neuropsychological studies in MCI for the assessment of conversion to AD. Neurobiol Aging 2006; 27: 24-31.

[57] Nobili F, De Carli F, Frisoni GB, et al. SPECT Predictors of Cognitive Decline and Alzheimer's Disease in Mild Cognitive Impairment. J Alzheimers Dis 2009; 17(4): 761-72.

[58] Staffen W, Bergmann J, Schonauer U, et al. Cerebral perfusion (HMPAO-SPECT) in patients with depression with cognitive impairment versus those with mild cognitive impairment and dementia of Alzheimer's type: a semiquantitative and automated evaluation. Eur J Nucl Med Mol Imaging 2009; 36: 801-10.

[59] Habert MO, Horn JF, Sarazin M, et al. Brain perfusion SPECT with an automated quantitative tool can identify prodromal Alzheimer's disease among patients with mild cognitive impairment. Neurobiol Aging 2009. [Epub ahead of print].

[60] Dougall NJ, Bruggink S, Ebmeier KP. Clinical use of SPECT in dementia - a quantitative review. In: Ebmeier KP, Ed. SPECT in Dementia. Basel: Karger Verlag 2003; pp. 4-37.

[61] Zakzanis KK, Graham SJ, Campbell Z. A meta-analysis of structural and functional brain imaging in dementia of the Alzheimer's type: a neuroimaging profile. Neuropsychol Rev 2003; 13: 1-18.

[62] De Santi S, de Leon MJ, Rusinek H, et al. Hippocampal formation glucose metabolism and volume losses in MCI and AD. Neurobiol Aging 2001; 22: 529-39.

[63] Nitrini R, Buchpiguel CA, Caramelli P, et al. SPECT in Alzheimer's disease: features associated with bilateral parietotemporal hypoperfusion. Acta Neurol Scand 2000; 101: 172-6.

[64] Silverman DHS, Small GW, Chang CY, et al. Positron emission tomography in evaluation of dementia - Regional brain metabolism and long-term outcome. J Am Med Assoc 2001; 286: 2120-7.

[65] Bonte FJ, Weiner MF, Bigio EH, White CL. Brain blood flow in the dementias: SPECT with histopathologic correlation in 54 patients. Radiology 1997; 202: 793-7.

[66] Jagust W, Thisted R, Devous MD, et al. SPECT perfusion imaging in the diagnosis of Alzheimer's disease - A clinical-pathologic study. Neurology 2001; 56: 950-6.

[67] Devous MD. Functional brain imaging in the dementias: role in early detection, differential diagnosis, and longitudinal studies. Eur J Nucl Med Mol Imaging 2002; 29: 1685-96.

[68] Jagust WJ. Functional imaging in dementia - an overview. J Clin Psych 1994; 55: 5-11.

[69] Kogure D, Matsuda H, Ohnishi T, et al. Longitudinal evaluation of early Alzheimer's disease using brain perfusion SPECT. J Nucl Med 2000; 41: 1155-62.

[70] Haxby JV, Grady CL, Koss E, et al. Longitudinal study of cerebral metabolic asymmetries and associated neuropsychological patterns in early dementia of the Alzheimer type. Arch Neurol 1990; 47: 753-60.

[71] Filippini N, MacIntosh BJ, Hough MG, et al. Distinct patterns of brain activity in young carriers of the APOE-epsilon4 allele. Proc Natl Acad Sci USA 2009; 106: 7209-14.
[72] Mentis MJ. Positron emission tomography and single photon emission computed tomography imaging in Alzheimer's disease. Neurologist 2000; 6: 28-43.

[73] Small GW, Rabins PV, Barry PP, et al. Diagnosis and treatment of Alzheimer disease and related disorders: consensus statement of the American association for geriatric psychiatry, the Alzheimer's association, and the American geriatrics society. J Am Med Assoc 1997; 278: 1363-71.

[74] Knopman DS, DeKosky ST, Cummings JL, et al. Practice parameter: diagnosis of dementia (an evidence-based review) - report of the quality standards subcommittee of the American academy of neurology. Neurology 2001; 56: 1143-53.

[75] Patterson CJ, Gauthier S, Bergman $\mathrm{H}$, et al. The recognition, assessment and management of dementing disorders: conclusions from the Canadian Consensus Conference on Dementia. Can Med Assoc J 1999; 160 (Suppl): S1-15.

[76] Gill SS, Rochon PA, Guttman M, Laupacis A. The value of positron emission tomography in the clinical evaluation of dementia. J Ame Gers Soc 2003; 51: 258-64.

[77] Braffman B, Drayer BP, Anderson RE, et al. Dementia: American college of radiology: ACR appropriateness criteria. Radiology 2000; 215 (Suppl): 525-33.

[78] Reisberg B, Burns A, Brodaty H, et al. Diagnosis of Alzheimer's disease: report of an international psychogeriatric association special meeting work group under the cosponsorship of Alzheimer's disease international, the European federation of neurological societies, the World Health Organization, and the World Psychiatric Association. Int Psychogeriatr 1997; 9 (Suppl 1): 11-38.

[79] Waldemar G, Dubois B, Emre M, et al. Recommendations for the diagnosis and management of Alzheimer's disease and other disorders associated with dementia: EFNS guideline. Eur J Neurol 2007; 14: e126.

[80] Waldemar G, Dubois B, Emre M, Scheltens P, Tariska P, Rossor M. Diagnosis and management of Alzheimer's disease and other disorders associated with dementia. The role of neurologists in Europe. European Federation of Neurological Societies. Eur J Neurol 2000; 7: 133-44.

[81] Dubois B, Picard G, Sarazin M. Early detection of Alzheimer's disease: new diagnostic criteria. Dialogues Clin Neurosci 2009; 11: 135-9.

[82] Dubois B, Feldman HH, Jacova C, et al. Research criteria for the diagnosis of Alzheimer's disease: revising the NINCDS-ADRDA criteria. Lancet Neurol 2007; 6: 734-46.

[83] Fairbairn A, Gould N, Kendall T, et al. Dementia: Supporting people with dementia and their carers in health and social care. London: National Institute for Health and Clinical Excellence 2006.

[84] Connelly P, Archibald C, Backet S, et al. Management of patients with demetia - a national clinical guideline. Edinburgh: Scottish Intercollegiate Guidelines Network 2006.

[85] Messa C, Perani D, Lucignani G, et al. High-resolution technetium99m-HMPAO SPECT in patients with probable Alzheimers-disease comparison with fluorine-18-FDG PET. J Nucl Med 1994; 35: 210-6.

[86] Ishii K, Hosaka K, Mori T, Mori E. Comparison of FDG-PET and IMP-SPECT in patients with dementia with Lewy bodies. Ann Nucl Med 2004; 18: 447-51.

[87] Dobert N, Pantel J, Frolich L, Hamscho N, Menzel C, Grunwald F. Diagnostic value of FDG-PET and HMPAO-SPET in patients with mild dementia and mild cognitive impairment: metabolic index and perfusion index. Dement Geriatr Cogn Dis 2005; 20: 63-70.

[88] Ishii K, Minoshima S. PET is better than perfusion SPECT for early diagnosis of Alzheimer's disease. Eur J Nucl Med Mol Imaging 2005; 32: 1463-5.

[89] Ebmeier KP, Filippini N, Mackay CE. Brain function and connectivity in dementia. In: Ames D, Burns A, O'Brien JT, editors. Dementia. $4^{\text {th }}$ ed. London: Hodder \& Stoughton 2010; [Epub ahead of print].

(C) Klaus P. Ebmeier; Licensee Bentham Open.

This is an open access article licensed under the terms of the Creative Commons Attribution Non-Commercial License (http: //creativecommons.org/licenses/by-nc/ $3.0 /$ ) which permits unrestricted, non-commercial use, distribution and reproduction in any medium, provided the work is properly cited. 